Zeszyty Naukowe Szkoły Głównej Gospodarstwa Wiejskiego w Warszawie

Problemy Rolnictwa Światowego tom 18 (XXXIII), zeszyt 4, 2018: 417-425

DOI: 10.22630/PRS.2018.18.4.130

Barbara Roszkowska-Mądra $^{1}$

Uniwersytet w Białymstoku

\title{
Koncepcja i znaczenie obszarów rolniczych o wysokich walorach przyrodniczych
}

\section{The Concept and Importance of High Nature Value Farmland}

\begin{abstract}
Synopsis. Koncepcja rolniczych obszarów HNV (ang. HNV farmland, lub HNVf) została wprowadzona do nauki i polityki gospodarczej Unii Europejskiej na przełomie dwóch ostatnich wieków, jako podstawa do skutecznych działań na rzecz przeciwdziałania dalszej redukcji bioróżnorodności na gruntach rolnych. Dotychczas ta ważna kwestia nie jest zadawalająco dyskutowana $\mathrm{i}$ prezentowana $\mathrm{w}$ piśmiennictwie polskim. W niniejszej pracy przeglądowej, stanowiącej przegląd i analizę europejskiej literatury naukowej, monografii i raportów unijnych, przedstawiono ważne zagadnienia, dotyczące definicji i typów rolniczych obszarów HNV, ich znaczenia przyrodniczego i gospodarczego oraz uzasadnienia realizacji programowej ochrony. Obszar rolniczy HNV stanowi grunty rolne, na których istnieje bogata bioróżnorodność o dużym znaczeniu dla ochrony gatunków, siedlisk i krajobrazów oraz stosowane sa ekstensywne systemy rolnicze, które sprzyjają dalszemu trwaniu lub wzbogacania istniejącej tam agro-bioróżnorodności. Obszary HNV pozwalają realizować wiele funkcji oraz dostarczać dóbr publicznych, środowiskowych i społecznogospodarczych. Uznaje się, że najlepszym sposobem ochrony wysokich walorów przyrodniczych obszarów rolniczych jest prowadzenie na nich ekstensywnej lub niskonakładowej gospodarki rolniczej. Dla spełnienia tego postulatu UE nakłada na kraje członkowskie obowiązek wdrażania koncepcji obszarów HNV, polegający głównie na ich delimitacji oraz wielostronnym i elastycznym wspieraniu rolników na tych terenach w ramach Wspólnej Polityki Rolnej i innych polityk krajowych.
\end{abstract}

Słowa kluczowe: Definicja obszarów HNV, funkcje obszarów HNV, ochrona obszarów HNV, WPR

\begin{abstract}
The concept of HNV farmland (HNVf) was introduced to the science and economic policy of the European Union at the turn of the last two centuries as a basis for effective measures to stop further reduction of biodiversity on farmlands. So far, this important issue has not been successfully discussed and presented in the Polish literature. In this review paper, based on European scientific literature, monographs and EU reports, important issues have been presented regarding the definition and types of HNVf, their environmental and economic importance and the justification for the implementation of program protection. HNV farmlands include those agricultural lands where rich agro-biodiversity exists - which is important for general protection of species, habitats and landscapes - and where they are accompanied by extensive or/and low-input farming systems. HNVf allow us to perform many functions and provide public, environmental and socio-economic goods. It is recognized that the best way to protect the high nature value of agricultural areas is to conduct on them extensive or low-input farming systems. In order to meet this demand, the EU imposes on Member States the obligation to implement the concept of HNVf, consisting mainly in their delimitation and flexible support for farmers in these areas under the Common Agricultural Policy and other national policies.
\end{abstract}

Key words: Definition of HNV farmland (HNVf), functions of HNVf, protection of HNVf, CAP

JEL Classification: Q18

\footnotetext{
${ }^{1}$ Dr hab. prof. UwB, Katedra Nauk o Przedsiębiorstwie UwB, ul. Warszawska 63, 15-062 Białystok, e-mail: broszkowska@poczta.onet.pl; orcid: 0000-0001-7713-9076
} 


\section{Wprowadzenie}

Rolnictwo jest dominującym sposobem użytkowania ziemi na świecie, zaś w Europie rozprzestrzenionym na ponad 45\% obszarów lądowych (Henle i in., 2008; Power, 2010; Lomba i in., 2014). Około 50\% wszystkich gatunków flory i fauny europejskiej zależy mniej lub bardziej od siedlisk rolniczych (EEA, 2006; Henle i in., 2008; Stoate i in., 2009; Halada i in., 2011; Lomba i in., 2014, 2015). Z powodu intensyfikacji rolnictwa, jego upraszczania i ograniczania lub rezygnacji z działalności rolniczej gospodarstw, od drugiej polowy XX wieku, ukształtowana przez wieki różnorodność biologiczna na wielu obszarach rolniczych w Europie stale ulega zawężaniu się (Strijker, 2005; Keenleyside i in., 2014; Lomba i in., 2014; Strohbach i in., 2015). To bardzo niekorzystne, wręcz groźne zjawisko permanentnego kurczenia się agro-bioróżnorodności zostało właściwie zauważone i ocenione na początku 90tych lat zeszłego wieku przez specjalistów europejskich (Baldock i in., 1993; Beaufoy i in., 1994). Przejawem ich podejścia do tego zjawiska było wprowadzenie pojęcia „obszar rolniczy o wysokich walorach przyrodniczych”, określanym jako „obszar rolniczy HNV” (ang. High Nature Value farmland, w skrócie $H N V$ farmland lub $H N V f)$. Pod wpływem postępu badań nad obszarami HNV i ewolucji terminologii w tym zakresie, w literaturze przedmiotowej coraz częściej, obok tradycyjnego pojęcia „obszar rolniczy HNV" używa się równoznacznego (niektórzy uważają że bliskoznacznego) określenia „rolnictwo HNV” (ang. HNV farming). W niniejszym opracowaniu będziemy posługiwali się tym pierwszym pojęciem, dopuszczając także nazwę skrótową „obszar HNV”. Obszar HNV jest kategorią pojęciową zarówno o znaczeniu przyrodniczo-rolniczym, jak i społeczno-ekonomicznym (Zielińska, 2013; Strijker, 2005; Keenleyside i in., 2014; Lomba i in., 2014).

W tematycznych monografiach i raportach władz i instytucji unijnych oraz w naukowej literaturze światowej i europejskiej w zakresie nauk rolniczych i ekonomicznych oraz nauk o ziemi, a zwłaszcza ich pogranicza, od prawie ćwierćwiecza dokumentowana jest obficie ogromna intelektualna aktywność polityczno-gospodarcza i prawna Unii Europejskiej oraz towarzysząca jej działalność naukowa, która dotyczy rolniczych obszarów HNV. Głównymi problemami, które są podejmowane w tych pracach odnoszą się do oceny znaczenia obszarów $\mathrm{HNV}$, adekwatnego wydzielania oraz charakterystyki przyrodniczo-rolniczej i ekonomicznej tych obszarów, wraz z monitoringiem ich występowania, a także dotyczą oceny skuteczności różnych narzędzi i środków wspierania obszarów HNV (Oppermann i in., 2012; Keenleyside i in., 2014; Europeen Commission, 2016). Publikacje te ilustrują ogromne znaczenie, jakie Unia Europejska nadaje rozwojowi i wdrażaniu koncepcji obszarów HNV, zgodnie z doktryną ochrony przyrody i paradygmatem rolnictwa zrównoważonego pod względem przyrodniczym, gospodarczym i społecznym (Lomba i in., 2014; Strohbach i in., 2015).

Jednakże, w Polsce, zarówno w sferze teoretycznej, jak i praktycznej nie obserwujemy podobnego zainteresowania obszarami HNV. Niewęgłowska i Zielińska (2010) wskazują, że Polska jest jednym z niewielu krajów członkowskich UE, który posiadał do 2010 roku jedynie wstępną koncepcję wyznaczenia na obszarach wiejskich Polski obszarów o wysokich walorach przyrodniczych (HNV) oraz opracowania dla tych obszarów monitoringu. W ramach tej koncepcji dokonano pierwszej - i dotychczas jedynej - próby delimitacji (zmapowania) obszarów HNV na obszarze całego kraju, a dokument ten został złożony oficjalnie do władz unijnych i jest opublikowany (Oppermann i in., 2012; Keenleyside i in., 2014). Niniejsza praca przeglądowa jest próbą przybliżenia polskiemu Czytelnikowi głównych zagadnień teorii i praktyki obszarów HNV, rozpatrywanych aktualnie w UE. 
Celem tej pracy, opartej na publikacjach naukowych, monografiach i raportach unijnych, jest 1) przedstawienie ważnych pojęć, poglądów i zagadnien dotyczących definicji i głównych typów rolniczych obszarów HNV, 2) charakterystyka znaczenia obszarów HNV oraz uzasadnienie ich programowej ochrony, 3) prezentacja wyników najważniejszych europejskich oraz krajowych badań naukowych i wdrożeniowych w tym zakresie.

\section{Definicja i główne typy obszarów rolniczych o wysokich walorach przyrodniczych}

Beaufoy i in., (1994) oraz Andersen i in. (2003) sprecyzowali istotę pojęcia „obszar rolniczy HNV" w postaci następującej definicji "Obszary rolnicze o wysokich walorach przyrodniczych (obszary HNV) sa tymi terenami w Europie, gdzie rolnictwo stanowi główny (zwykle dominujacy) rodzaj użytkowania ziemi, sprzyjajac wysokiej różnorodności gatunkowej i siedliskowej, a także (albo) występowaniu gatunków o dużym znaczeniu dla ochrony przyrody w skali europejskiej”. Uznaje się, że głównym warunkiem utrzymania i pożądanego kształtowania rolniczych obszarów HNV, czyli rolnictwa HNV jest ekstensywna i mało intensywna gospodarka rolnicza, ale zapewniająca żywotność egzystencjalną i ekonomiczną ludności rolniczej tam mieszkającej (Bignal i McCracken, 1996, 2000; Andersen i in., 2003; Strijker, 2005; Halada i in., 2011; Lomba i in., 2014). Wobec tego, o istnieniu rolniczych obszarów HNV (rolnictwa HNV) decyduje współistnienie dwóch bytów. Jednym z nich jest określony, fizyczno-środowiskowy obszar rolniczy HNV (ang. HNV farmland), rozumiany jako ta wyróżniona część obszaru rolniczego, tj. obszaru gruntów rolnych (obejmującego użytki rolne oraz nieużytki rolne), na której istnieje bogata bioróżnorodność o dużym znaczeniu dla ochrony gatunków, siedlisk i krajobrazów (EEA, 2012; Oppermann i in., 2012; Keenleyside i in., 2014; Europeen Commission, 2016). Drugim bytem sa stosowane na tych terenach ekstensywne i mało intensywne systemy gospodarki rolniczej, które sprzyjają dalszej dynamice naturalnych procesów oraz tworzeniu warunków dla trwania lub nawet poszerzania (wzbogacania) istniejącej tam agro-bioróżnorodności (Henle i in., 2008; Paracchini i in., 2008; Beaufoy i Cooper, 2009; Keenleysideean i in., 2014; Lomba et al., 2014; Strohbach i in., 2015). Takie systemy gospodarki rolniczej, wyrażające się niską obsadą zwierząt na 1 ha użytków rolnych, wysokimi nakładami pracy, małym poziomem mechanizacji, stosowaniem odłogów, niskim zużyciem chemikaliów i nawodnienia, są nazywane w najnowszej literaturze, systemami HNV, ang. HNV farming systems (Van Doorn i Elbersen, 2012; Ribeiro i in., 2014). Są one często badane pod kątem ich identyfikacji, oceny różnorodności (typologii) i monitoringu, zwłaszcza w aspekcie pogłębionej oceny obszarów HNV oraz doskonalenia strategii i scenariuszy wspierania ich ochrony i rozwoju w ramach Wspólnej Polityki Rolnej (Lomba i in., 2014, 2015; Ribeiro i in., 2014; Strohbach i in., 2015). W przedmiotowej literaturze naukowej, badawczo-rozwojowej i polityczno-gospodarczej stwierdza się wyraźnie, że dość nowe i słabo utrwalone pojęcia „HNV farmland” oraz „HNV farming systems”, choć są ściśle powiązane merytorycznie, to jednak stanowią różne, komplementarne kategorie charakteryzujące obszary rolnicze HNV (rolnictwo HNV). Zatem, te dwa pojęcia nie mogą być używane zamiennie. Każde z nich jest wyrazem fizycznych, środowiskowych, społecznych i ekonomicznych aspektów obszaru rolniczego i gospodarki sprzyjającej jego dużym walorom przyrodniczym (Zielińska, 2013; Strijker, 2005; Keenleyside i in., 2014; Lomba i in., 2014). 
W bardziej rozwiniętym ujęciu wysoka wartość przyrodnicza jest przypisywana tym obszarom rolniczym, które charakteryzują się 1) wysokim udziałem naturalnej i/lub półnaturalnej roślinności, trwale przystosowanej do warunków siedliskowych (głównie ekstensywnych trwałych użytków zielonych, pastwiskowych terenów rolniczo-leśnych, lasów na użytkach rolnych, starych sadów itp.) oraz 2) mozaiką gruntów ornych i użytków trwałych, wzbogaconą rozproszonymi nieużytkami rolniczymi, zarówno naturalnymi, jak i pół-naturalnymi (śródpolnymi zadrzewieniami, zakrzewieniami, zaroślami, mokradłami, ciekami wodnymi etc.), na których stosuje się głównie ekstensywne systemy gospodarki rolniczej z niską obsadą zwierząt, stosowaniem odłogów między polowymi roślinami uprawnymi oraz niskim zużyciem nawozów mineralnych, środków ochrony roślin i nawodnień pól uprawnych (EEA, 2004; Beaufoy i Cooper, 2009; Lomba i in., 2014, 2015). Andersen i in. (2003) wprowadzili definicję trzech typów obszarów HNV, które później zostały nieco zmodyfikowane (Paracchini i in., 2006, 2008; Lomba i in., 2014): Typ 1 - obszary rolnicze użytkowane ekstensywnie z wysokim udziałem roślinności półnaturalnej lub/i nieużytków naturalnych; Typ 2 obszary rolnicze użytkowane przeważnie ekstensywnie lub/i mało intensywnie, z niższym udziałem roślinności pół-naturalnej, wysoką różnorodnością (mozaikowatością) krajobrazu, a także obecnością rozproszonych nieużytków naturalnych; Type 3 - obszary rolnicze (włączając intensywnie użytkowane grunty orne i trwałe użytki zielone), które są naturalnym siedliskiem występowania lub/i rozrodu chronionych gatunków zwierząt, zwłaszcza ptaków. W rzeczywistości te trzy typy obszarów HNV nie są wyróżnione ostrymi granicami, zaś mogą pokrywać się w różnym stopniu. Taka koegzystencja dotyczy głównie obszarów HNV typu 1 i 2, co utrudnia w praktyce dokonanie trafnej kategoryzacji tych obszarów w zakresie lokalnym, regionalnym, krajowym lub europejskim (Peppiette i in., 2012; Lomba i in., 2014).

\section{Znaczenie obszarów HNV i uzasadnienie ich programowej ochrony}

Rolnicze obszary HNV w każdym kraju są ważnym dobrem narodowym, długo kształtowanym dziedzictwem przyrodniczo-kulturowym, oferowanym społeczeństwu przez rolnictwo wielofunkcyjne w ramach polityki unijnej (Power, 2010; Sullivan i in., 2017). Obszary te pozwalają realizować wiele celów, funkcji oraz dostarczać dóbr publicznych, zarówno środowiskowych (ekologicznych lub ekosystemowych), jak i społecznogospodarczych. Należą do nich trwałe zapewnienie 1) wysokiego stopnia bioróżnorodności obszarów rolniczych (znaczący udział w całościowym systemie ochrony przyrody danego kraju), 2) osobliwego piękna oraz turystyczno-rekreacyjnej i osiedleńczej atrakcyjności krajobrazów wiejskich, 3) dobrej jakości wody, powietrza i gleby w wąskiej i szerszej skali przestrzennej, 4) regulacji klimatu i ochrony przed powodziami, 5) produkcji wysoko jakościowej żywności ekologicznej i specjalistycznej oraz 6) zrównoważonego rozwoju wsi i rolnictwa ze szczególnym uwzględnieniem żywotności społeczno-ekonomicznej ludności wiejskiej (Zielińska, 2013; Power, 2010; Keenleyside i in., 2014; Lomba i in., 2014, 2017; Strohbach i in., 2015; Sullivan i in., 2017). Zatem, obszary HNV wymagają świadomej i dobrze zorganizowanej, długoterminowej ochrony ich wysokiej wartości przyrodniczej, poprzez wsparcie publiczne. Wspierając ich ochronę, uskuteczniamy i optymalizujemy realizację wymienionych celów. Dlatego, obszary HNV są ważnym przedmiotem rolniczych i ekonomicznych badań naukowych i wdrożeniowych oraz sprzężonych z nimi, zainteresowań strategów, analityków, polityków i decydentów gospodarczych w zakresie 
politycznego wspierania rolnictwa (Henle i in., 2008; Oppermann in., 2012; Keenleyside i in., 2014; Lomba i in., 2014, 2015).

Według badań wykonanych przez Europejską Agencję Środowiskową dla wszystkich krajów unijnych za 2006 rok (EEA 2012), przeciętny udział powierzchni obszarów HNV w UE stanowił wówczas około $40 \%$ powierzchni gruntów rolnych, tj. łącznie użytków rolnych (UR) oraz nieużytków rolnych (obszarów o niekorzystnej rzeźbie terenu, zadrzewień, zarośli, torfowisk, mokradeł itp.). W Polsce obszary HNV obejmowały 22,7\% gruntów rolnych, zaś 30\% UR. Istnieje bardzo duże zróżnicowanie pomiędzy państwami członkowskimi Unii Europejskiej pod względem udziału rolniczych obszarów HNV w ogólnej powierzchni gruntów rolnych (od ok. 5\% w Danii do 90-100\% w Norwegii i Islandii). Udział obszarów HNV jest największy w północno-zachodniej, północnej, południowej i wschodniej Europie, zwłaszcza w rejonach górskich, podgórskich i wyżynnych (EEA, 2012; Van Doorn i Elbersen, 2012; Oppermann i in., 2012; Keenleyside i in., 2014). Obszary HNV są zlokalizowane głównie na obszarach ONW w Unii Europejskiej, gdzie warunki przyrodnicze ograniczają intensywniejsze gospodarowanie (EEA, 2004, 2006, 2012; Paracchini i in., 2006, 2008; Keenleyside i in., 2014)

Obszary HNV podlegają wielu długoterminowym i współczesnym zagrożeniom, głównie ze strony intensyfikacji i globalizacji rolnictwa, albo też na skutek upraszczania (małej dywersyfikacji) systemów gospodarki rolniczej lub porzucania i degradacji działalności rolniczej na tych terenach i pojawiania się sukcesji wtórnej rodzimej roślinności (Strijker, 2005; Lomba $\mathrm{i}$ in. 2014; Terres $\mathrm{i}$ in. 2015). Zagrożenia te sa rezultatem głównie 1) braku należytego docenienia i uznania wysokiej wartości przyrodniczej obszarów HNV oraz rolników tam gospodarujących w wielu krajach unijnych, 2) braku swoistego i skutecznego wspierania publicznego $\mathrm{w}$ obecnej i proponowanej reformie WPR, 3) słabej żywotności ekonomicznej obszarów HNV i satysfakcji rolników, stosujących systemy HNV, w porównaniu do innych systemów gospodarowania (Strohbach $i$ in. 2015). Zatem, głównym ideowym, politycznym i administracyjnym zadaniem wszystkich władz państwowych i samorządowych, odpowiedzialnych za zachowanie wysokiej przyrodniczej wartości obszarów HNV, wraz z permanentnym świadczeniem ekosystemowych i społeczno-ekonomicznych dóbr publicznych, jest poprawa społeczno-ekonomicznej żywotności systemów gospodarowania HNV na tych terenach (EEA 2006, 2012; Keenleyside i in., 2014).

Według obecnych poglądów, wypracowanych przez ekologów, najlepszym sposobem zachowania bioróżnorodności obszarów HNV i (przez to) ochrony wysokich walorów przyrodniczych tych krajobrazów, jest prowadzenie na nich ekstensywnej gospodarki rolniczej, czyli rolniczego wykorzystania ziemi, zgodnie z doktryną, że „Ochrona tego co jeszcze pozostało jest ważniejsza, niż przywracanie, tego co zostało utracone” (Kleijn i in., 2009; Lomba i in., 2014). Wszakże, rolnik jest kustoszem i architektem każdego obszaru rolniczego i do niego należy główna decyzja, dotycząca tego, jak gospodarować we własnym gospodarstwie. Jednakże, rolnik odpowiednio uświadamiany, przekonywany i zachęcany ekonomicznie, może wdrażać takie systemy gospodarowania rolniczego, które pozwolą lepiej wydobyć, ukazać oraz utrwalić niepowtarzalne piękno natury, wkomponowane w krajobraz obszarów wiejskich. Dalsze istnienie i rozwój przyrodniczoekonomiczny rolniczych obszarów HNV wymagaja permanentnego stosowania na nich niskonakładowych, ekstensywnych lub pół-intensywnych metod gospodarowania (Strijker 2005; Beaufoy i Cooper 2009; Keenleyside i in., 2014; Lomba i in., 2014, 2017). Dla 
niezawodnej realizacji tego warunku wymagane jest wdrażanie koncepcji obszarów HNV, polegające głównie na wielostronnym, elastycznym i możliwie trafnym wspieraniu rolników na tych terenach w ramach Wspólnej Polityki Rolnej, WPR (Zielińska, 2013; Lomba i in., 2014, 2017; Strohbach i in., 2015). Dla zapewnienia warunków do efektywnego wdrażania narzędzi wspierania obszarów HNV w ramach WPR i krajowej polityki gospodarczej, UE nakłada na każdy kraj unijny zobowiazzanie do identyfikacji, pogłębionej charakterystyki (typologii) i monitoringu zmian tych obszarów oraz oceny efektywności programów rolno-środowiskowych (Kleijn i Sutherland, 2003; Henle i in., 2008; EEA 2012; Keenleyside i in., 2014; Lomba i in., 2014, 2017). Niestety, utrudnienia $\mathrm{w}$ dostępności do baz danych odnośnie szczegółowego pokrycia ziemi i agrobioróżnorodności oraz brak jednolitej wspólnej metodyki wydzielania i mapowania obszarów HNV w krajach UE, stwarzają poważne trudności i ograniczenia w skutecznym wdrażaniu koncepcji obszarów HNV (Oppermann i in., 2012; Keenleyside i in., 2014; Lomba i in., 2014, 2017; Strohbach i in., 2015; Sullivan i in., 2017).

\section{Podsumowanie}

Obszary HNV pozwalają realizować wiele celów i funkcji oraz dostarczać dóbr publicznych, zarówno ekologicznych lub ekosystemowych, jak i społeczno-gospodarczych. Obejmują one trwałe zapewnienie możliwie dużej agro-bioróżnorodności, unikalnego piękna tradycyjnej wiejskiej przestrzeni krajobrazowej oraz jej atrakcyjności turystycznorekreacyjnej i osiedleńczej, dzięki dobrej jakości wody, powietrza i gleby wraz z możliwością wytwarzania żywności wysoko jakościowej. Z drugiej strony, rolnicze obszary HNV, zarówno w Polsce, jak i poza nią, muszą być tak umiejętnie rozwijane i wspierane w sposób zrównoważony, aby nie nadwyrężyć fundamentów ich istnienia, czyli żywotności społecznej i ekonomicznej ludności rolniczej tam mieszkającej i pracującej w oparciu o swoje gospodarstwa rolne. Ta ludność przez wieki całe jest solą obszarów HNV. Stanowi ona wyjątkowo tradycyjne społeczności rolników-kustoszy swoich gruntów rolnych, zżytych silnie ze swoją ziemią i z determinacją dbających o swój godziwy byt, ale też dbających o ochronę matki natury. Oni zawsze tak czynili, dlatego im zawdzięczamy obecne istnienie (zachowanie przed degradacja) obszarów HNV w Polsce oraz innych krajach Europy i świata. Zgodnie ze zdrowym rozsądkiem, świadomością historyczną i znajomością praw dziejów społecznych, co jest wyrażone tak pięknie w postaci unijnej koncepcji „rolnicze obszary HNV”, UE, władze państw członkowskich i samorządów różnych szczebli powinny tylko dobrze (roztropnie, sprawiedliwie dla całego społeczeństwa i odczuwalnie dla rolników) wspierać materialnie (finansowo i poprzez środki towarzyszące), duchowo (danie satysfakcji, uznania, docenienie) oraz intelektualnie (kształcenie, doradztwo, stały dopływ informacji merytorycznej, szkolenia, dyskusja partnerska itp.) rolników mieszkających i pracujących na obszarach HNV i/lub obszarach zmierzających do znalezienia się $\mathrm{w}$ tej kategorii. Dla zapewnienia warunków do efektywnego wdrażania narzędzi publicznego wspierania obszarów HNV w ramach WPR i krajowej polityki gospodarczej, UE nakłada na każdy kraj unijny zobowiązanie do identyfikacji, pogłębionej charakterystyki (typologii) i monitoringu dynamiki obszarów HNV oraz oceny efektywności programów rolno-środowiskowych w zakresie ochrony i kształtowania rozważanych obszarów. Realizacja tego trudnego zadania wymaga zintegrowanych i skoordynowanych prac politycznych, eksperckich, naukowych i 
administracyjnych, zarówno w skali międzynarodowej, jak i wewnątrzkrajowej. W świetle literatury przedmiotu i oficjalnych raportów unijnych, w Polsce stan tych prac jest dalece niezadawalający.

\section{Literatura}

Andersen, E, Baldock, D., Bennett, H., Beaufoy, G., Bignal. E., Brouwer, F., Elbersen, B., Eiden, G., Godeschalk, F., Jones, G., McCracken, D.I., Nieuwenhuizen, W., van Eupen, M., Hennekens, S., Zervas, G. (2003). Developing a High Nature Value Indicator. Report for the European Environment Agency, Copenhagen.

Baldock, D., Beaufoy, G., Bennett, G., Clark, J. (1993). Nature conservation and new directions in the Common Agricultural Policy. IEEP, London.

Beaufoy, G., Baldock, D., Clark, J. (1994). The nature of farming: Low intensity farming systems in nine European countries. IEEP, London.

Beaufoy, G., Cooper, T. (2009). The Application of the High nature Value Impact Indicator. Report by European Evaluation Network for Rural Development.

Bignal, E.M., McCracken, D.I. (2000). The nature conservation value of European traditional farming systems. Environmental Reviews, 8, 149-171.

Bignal, E.M., McCracken, D.I. (1996). Low-intensity farming systems in the conservation of the countryside. Journal of Applied Ecology, 33, 413-424.

EEA (2004). High Nature Value farmland - characteristics, trends and policy challenges. EEA, European Environment Agency, Copenhagen.

EEA (2006). Land Accounts for Europe 1990-2000. Towards integrated land and ecosystem accounting. EEA, European Environment Agency, Copenhagen.

EEA (2012). Updated High Nature Value farmland in Europe: an estimate of the distribution patterns on the basis of CORINE land cover 2006 and biodiversity data. The draft EEA Technical Report on a basis of the ETC SIA IP 2011 Task 421 implementation.

EUROPEAN COMMISSION - Directorate-General for Agriculture and Rural Development - Unit E.4 (2016). Report. Preparing the assessment of HNV Farming in RDPs 2014-2020: practices and solutions. Good Practice Workshop, Bonn 7-8 June 2016, Brussels.

Halada, L., Evans, D., Romão, C., Petersen, J.E. (2011). Which habitats of European importance depend on agricultural practices? Biodiversity and Conservation, 20, 2365-2378.

Henle, K., Alard, D., Clitherow, J., Cobb, P., Firbank, L., Kull, T., McCracken, D., Moritz, R.F.A., Niemela, J., Rebane, M., Wascher, D., Watt, A., Young, J. (2008). Identifying and managing the conflicts between agriculture and biodiversity conservation in Europe - A review. Agriculture, Ecosystems and Environment, 124, 60-71.

Keenleyside, C., Beaufoy, G., Tucker, G., Jones, G. (2014). High Nature Value farming throughout EU-27 and its financial support under the CAP. Report Prepared for DG Environment, Contract No ENV B.1/ETU/2012/0035, Institute for European Environmental Policy, London.

Kleijn, D., Sutherland, W.J. (2003). How effective are European agri-environment schemes in conserving and promoting biodiversity? Journal of Applied Ecology, 40, 947-969. 
Kleijn, D., Kohler, F., Báldi, A., Batáry, P., Concepción, E.D., Clough, Y., Díaz, M., Gabriel, D., Holzschuh, A., Knop, E., Kovács, A., Marshall, E.J.P., Tscharntke, T., Verhulst, J., (2009). On the relationship between farmland biodiversity and land-use intensity in Europe. Proceeding of the Royal Society Biological Sciences, 276, $903-$ 909.

Lomba A., Alves P., Jongman R.H.-G., McCracken D.I. (2015). Reconciling nature conservation and traditional farming practices: a spatially explicit framework to assess the extent of High Nature Value farmlands in the European countryside. Ecology and Evolution, 5, 1031-1044.

Lomba A., Guerra C., Alonso J., Honrado J.P., Jongman R., McCracken D. (2014). Mapping and monitoring High Nature Value farmlands: Challenges in European landscapes. Journal of Environmental Management, 143, 140-150.

Lomba A., Strohbach M., Jerrentrupd J. S., Dauberd J., Klimek S., McCracken D.I. (2017). Making the best of both worlds: Can high-resolution agricultural administrative data support the assessment of High Nature Value farmlands across Europe? Ecological Indicators, 72, 118-130.

Niewęgłowska G., Zielińska A. (2010). Obszary wiejskie o wysokiej różnorodności biologicznej i krajobrazowej, a ekstensywna gospodarka rolna (HNV farmlands in Poland, and extensive and traditional farming). Niepublikowany referat na seminarium IERiGR, Warszawa 25 czerwca $2010 \mathrm{r}$.

Oppermann, R., Beaufoy, G., Jones, G. (eds). (2012). High Nature Value Farming in Europe. 35 European countries - experiences and perspectives. Verlag Regionalkultur, Ubstadt-Weiher, Germany.

Paracchini, M.L., Petersen, J.-E., Hoogeveen, Y., Bamps, C., Burfield, I., Van Swaay, C., (2008). High Nature Value Farmland in Europe - an Estimate of the Distribution Patterns on the Basis of Land Cover and Biodiversity Data. JRC Scientific and Technical Reports. Joint Research Centre - Institute for Environment and Sustainability, Luxembourg.

Paracchini, M.L., Terres, J.M., Petersen, J.E. and Hoogeveen, Y. (2006). Background Document on the Methodology for Mapping High Nature Value Farmland in EU27. European Commission Directorate General Joint Research Centre and the European Environment Agency.

Peppiette, Z., Oppermann, R., Benzler, A., Beaufoy, G., McCracken, D. (2012). Approaches to monitoring HNV farming - EU framework and country examples. In: Oppermann, R., Beaufoy, G., Jones, G. (Eds.), High Nature Value Farming in Europe. Verlag Regionalkultur, Ubstadt-Weiher, Heidelberg, Basel, 502-516.

Power, A.G. (2010). Ecosystem services and agriculture: tradeoffs and synergies. Philosophical Transactions of the Royal Society B, 365, 2959-2971.

Ribeiro, P.F., Santos, J.L., Bugalho, M.N., Santana, J., Reino, L., Beja, P., Moreira F. (2014). Modelling farming system dynamics in High Nature Value Farmland under policy change. Agriculture, Ecosystems and Environment, 183, 138-144.

Stoate, C., Baldi, A., Beja, P., Boatman, N.D., Herzon, I., van Doorn, A., de Snoo, G.R., Rakosy, L., Ramwell, C. (2009). Ecological impacts of early 21st century agricultural change in Europe - A review. Journal of Environmental Management, 91, 22-46.

Strijker, D. (2005). Marginal lands in Europe - causes of decline. Basic and Applied Ecology, 6, 99-106. 
Strohbach, M.W., Kohler, M.L., Dauber, J., Klimek, S. (2015). High Nature Value farming: From indication to conservation. Ecological Indicators, 57, 557-563.

Sullivan, C.A., Finn, J.A., Ó hÚallacháin, D., Green, S., Matin, S., Meredith, D., Cli $\square$ ordd, B., Moran, J. (2017). The development of a national typology for High Nature Value farmland in Ireland based on farm-scale characteristics. Land Use Policy, 67, 401-414.

Terres, J.M., Scacchiafichi, L.N., Wania, A., Ambar, M., Anguiano, E., Buckwell, A., Coppola, A., Gocht, A., Källström, H.N., Pointereau, P., Strijker, D., Visek, L., Vranken, L., Zobena, A. (2015). Farmland abandonment in Europe: identification of drivers and indicators, and development of a composite indicator of risk. Land Use Policy, 49, 20-34.

van Doorn, A.M., Elbersen, B.S. (2012). Implementation of High Nature Value farmland in agri-environmental policies: What can be learned from other EU Member States? Alterra, Wageningen, Alterra Report.

Zielińska, A. (2013). Gospodarowanie na obszarach przyrodniczo cennych w Polsce w kontekście rozwoju zrównoważonego (Farming on HNV farmlands in Poland in the context of sustainable development). Wydawnictwo UE we Wrocławiu, Wrocław.

Do cytowania / For citation:

Roszkowska-Mądra B. (2018). Koncepcja i znaczenie obszarów rolniczych o wysokich walorach przyrodniczych. Problemy Rolnictwa Światowego, 18(4), 417-425;

DOI: 10.22630/PRS.2018.18.4.130

Roszkowska-Mądra B. (2018). The Concept and Importance of High Nature Value Farmland (in Polish). Problems of World Agriculture, 18(4), 417-425; DOI: 10.22630/PRS.2018.18.4.130 